\title{
Final Scientific/Technical Report for \\ Building Transmission Capacity in the Western Interconnection \\ to Support a Low Carbon Future
}

\author{
U.S. Department of Energy \\ Grant Award Number DE-EE0000499 \\ Report Number: DOEFR3312011
}

\section{From Center for Energy Efficiency and Renewable Technology (CEERT) and Western Grid Group}

This report is the final report for the above mentioned contract. The project period was from December 1, 2009 to November 30, 2010. The deliverables for this project include a website www.westergrid.net and the report "The Best of the West Policies and Practices to Support Transition to a Lower-Carbon Electric Sector in the Western Interconnection".

Working Partners for the project include:

Amanda Ormond: 7650 S. McClintock Drive, Ste 103-282, Tempe, AZ 85284

Roger Hamilton: 511 Brookside Dr. Eugene, OR 97405

Ron Lehr: 4950 Sanford Circle West, Englewood, CO 80113

Distribution limitations

There is no limitation on the distribution of this Final Report or the deliverable report.

\section{Executive Summary}

1) How the research adds to the understanding of the area investigated

The grant, Building Transmission Capacity in the Western Interconnection to Support a Low Carbon Future, was funded from the 20\% Wind by 2030 - Overcoming Challenges grant program. The program focused, in part, on the need to "communicate the wind development opportunities, benefits, challenges, and required infrastructure upgrade and regulatory actions to a diverse set of stakeholders." Correctly, the DOE recognizes "utilities and States as essential stakeholders and critical to the success of market acceptance" of wind.

The Building Transmission Capacity grant activities focused on educating both policy makers (primarily at Public Utility Commissions) and utilities across the West. Western Grid Group (WGG), the grant recipient, chose three methods to reach these audiences - direct outreach, a website that contains information on policies and strategies to integrate more variable generation resources, and a report "The Best of the West, Policies and Practices to Support Transition to a Lower-Carbon Electric Sector in the Western Interconnection" that highlights what is working in the West. While all avenues for education are effective the Best of the West

Published by Center for Energy Efficiency and Renewable Technologies and Western Grid Group March 31, 2011 
report is the first west-wide assessment of its kind. The report details incremental changes that are working to integrate variable generation but it also expounds on what fundamental or transformative changes are needed to get to the $20 \%$ wind penetration and beyond.

\section{2) Technical effectiveness and economic feasibility of the methods or techniques investigated or demonstrated}

The technical effectiveness of this project was high as specific policies and practices from throughout the West were assessed and ranked. This allows states, regional organizations, elected officials and utilities to compare their programs to others and learn what leaders are doing. The cost of the project was highly leveraged, with the DOE providing only a portion of the total funds, so the economic feasibility for the project was also good. DOE provided $25 \%$, totaling $\$ 100,000$ of the budget and partners provided $75 \%$, totaling $\$ 300,000$. Using the internet to communicate information is very cost-effective. Having a website and report to reference when working one-on-one with decision makers provided a cost-effective means to convey information.

\section{3) How the project is otherwise of benefit to the public}

The transition to clean energy will provide multiple benefits for the public. Wind and other renewable energy resources are stable in price, lack emissions that can be harmful to and costly to public and are locally (domestically) produced. Deploying renewable energy more quickly and efficiently, the goal of this grant, will bring these benefits to the public faster. When utilities and regulators have fact-based, appropriate information they can make better decision on behalf of customers. The work funded under this grant helped to increase the rate of transition to a clean energy future.

\section{Comparison of the actual accomplishments with the goals and objectives of the project}

The objectives of this project were to increase the understanding of utility personnel and utility regulators; be a consistent, credible, and ever-present voice for wind and renewable energy resources; and encourage the implementation of policies and practices to expand the grid.

This project has accomplished all three objectives. In-person education has taken place in the states of Arizona, California, Utah, Colorado, Washington, Oregon, Montana, and Nevada. In addition WGG has participated in numerous westwide venues to educate and advocate for supportive policy. The west is considering new innovative programs, such as development of the westwide Energy Imbalance Market (EIM), that will share reserves and support wind energy. Regional policies such as the EIM and local projects, such as good wind integration studies, work the integration issue from all sides - individual utility action to westwide action. WGG is a strong advocate for all the market policies that will strengthen planning and building of the grid of the future. Finally, the website developed by WGG provides $24 / 7$ information on a wide range of topics supporting variable generation.

\section{Summary of project activities for the entire period of funding}

To meet our objectives WGG deployed eight knowledgeable people in eight key states to work directly with regulators, utilities and other stakeholders. Each staff member was responsible

Published by Center for Energy Efficiency and Renewable Technologies and Western Grid Group March 31, 2011 
for identifying the appropriate venues and messages to be delivered in that state. For this reason WGG only hires high-level, experience personnel (six of the eight WGG advocates are former public utility commissioners). Education took the form of one-on-one conversations, presenting at conferences and workshops, and participating in PUC and utility workshops.

Utilizing experience policy people also helped accomplish our second objective to be a consistent, credible voice for wind and renewable. In this regard WGG wanted to develop a website to build our profile and credibility and to be a source of information for those not deeply steeped in energy issues. We designed a website that is accessible to emerging stakeholders such as environmental and land organizations, consumer advocates and local governments. Our original intent was to develop a simple website in the first few months of the contract period. However, with funds from our foundation partner we were able to develop a robust professional-looking website with state-of-the-art graphics and function. The website did not become live until the end of the project period (one year). See www.westgrid.net

Our third object was to encourage the implementation of policies and practices to expand the grid. To encourage adoption of new policies related to variable generation it was first necessary to assess what is in place now, who is doing what, and how effective are the current policies and programs. When originally envisioned, the market report was going to be a brief summary of the West and some of the best policies. However, when we got into the development of such a product we realized that such an effort, if it was to be useful, would need to be comprehensive and detailed. Again, with supplemental funding from a foundation, we were able to produce a very thorough assessment of the entire Western Interconnection. To develop the report the eight WGG members met twice. Drafts and revision were developed over a six month period. The final report was send to DOE for a review and it was finalized at the close of the project period. On the negative side the report took significantly longer and more resources then envisioned. On the positive side the effort helped to organize how policy changes could be categorized, who the leader are, and it helped to focus work in different states.

$\underline{\text { Identify products developed under the award and technology transfer activities }}$

\section{Publications:}

Building Transmission Capacity in the Western Interconnection to Support a Low Carbon Future. The report contains a 14 page summary report, a matrix of incremental and transformative policies by sub-regional planning group, and a 28 page appendix of examples of exemplary programs and policies in the west.

Web site:

The WGG website created can be found at www.westerngrid.net

Published by Center for Energy Efficiency and Renewable Technologies and Western Grid Group March 31, 2011 